\title{
Flow Characteristics at the Pump-Turbine Interface of a Torque Converter at Extreme Speed Ratios
}

\author{
A. Habsieger and R. D. Flack \\ Department of Mechanical and Aerospace Engineering, University of Virginia, Charlottesville, \\ Virginia, USA
}

The average velocity field at the pump-turbine interface in a scaled version of a truck torque converter was studied. Seven different turbine-to-pump rotational-speed ratios were examined, ranging from near stall $(0.065)$ to overspeed (1.050) so as to determine the effect of the speed ratio on the flow field and on the mass flow rate. Laser velocimetry was used to measure the flow velocity through the pump's exit and the turbine's inlet plane. At the pump's exit, as the speed ratio increases, the high velocities move to the pressure-shell corner and then to both the core-suction and the pressureshell corners. Concentrated velocity gradients are largest at the lowest speed ratio, but areas of velocity gradients are largest near the coupling point. Near the coupling point, the flow field is most nonuniform, which yields a highly periodic flow into the turbine inlet. Above the coupling point, the high velocity remains in the pressure-shell corner but separation is seen to develop at the highest speed ratio. At the turbine's inlet, reverse flow is seen at low speed ratios and is an indicator of flow leakage through the core. Velocity gradients are very large at low speed ratios. As the speed ratio increases to the coupling point, the high velocities remain on the shell side. Above the coupling point, the high-velocity flow migrates from the shell side to the core side. The mass flow rate decreases significantly and nonlinearly with the increase of the speed ratio, but for speed ratios greater than 1.000, the negative slope decreases.

Received 25 June 2002; accepted 1 July 2002.

General Motors Corporation Powertrain Division sponsored part of this research. The authors express their gratitude to D. Maddock for his expertise and the technical and hardware support. The research was also supported in part by the Rotating Machinery and Controls Laboratory at the University of Virginia.

Address correspondence to R. D. Flack, Department of Mechanical and Aerospace Engineering, University of Virginia, Charlottesville, Virginia 22903-2442. E-mail: rdf@ virginia.edu

Keywords Laser velocimetry, Pumps, Torque converters, Turbines

Torque converters are commonly used in cars, buses, locomotives, and construction equipment as a mean of smooth torque transmission between the engine and the automatic transmission and to provide torque amplification during start-up conditions. The typical torque converter is a recirculating hydrodynamic, mixed-flow turbomachine (containing both radial and axial flow) with three independent blade cascade elements that govern the internal flow field. These three elements are the pump, which energizes the working fluid and which is connected to the engine; the turbine, which extracts the energy from the flow and translates it into output torque; and the stator which, ideally, redirects the turbine's exit flow back into the pump with a zero flow incidence at a specific design speed ratio. The pump and turbine are rotating at different angular speeds while the stator is either locked or allowed to float freely. Because of the significant curvature of the flow path and the high interaction among these three elements, the internal flow field is highly three-dimensional.

The flow field, the torque, and the efficiency curves are normally determined only from the zero speed ratio (turbine has stopped) to the coupling point (turbine torque and pump torque are equal), which typically occurs at a speed ratio of 0.85 to 0.90 . Performance characteristics are normally required only in the range from stall to cruise. A torque converter, however, can be operated at high positive speed ratios beyond the cruise point. Therefore, positive speed ratios greater than 1.0 indicate that the turbine is overrunning, or exceeding the speed of the pump's impeller.

Others have performed studies of the flow fields in torque converters, including Browarzik (1994), Ejiri and Kubo (1998), Marathe and Lakshminarayana (1997), and Watanabe and colleagues (1997). Efforts at the University of Virginia have used nonintrusive laser velocimetry to map out the detailed flow fields discussed by, for example, Brun and Flack (1994) and Whitehead (1995).

The experimental test facility had been previously developed and described in Claudel (1997), Whitehead (1995), and 


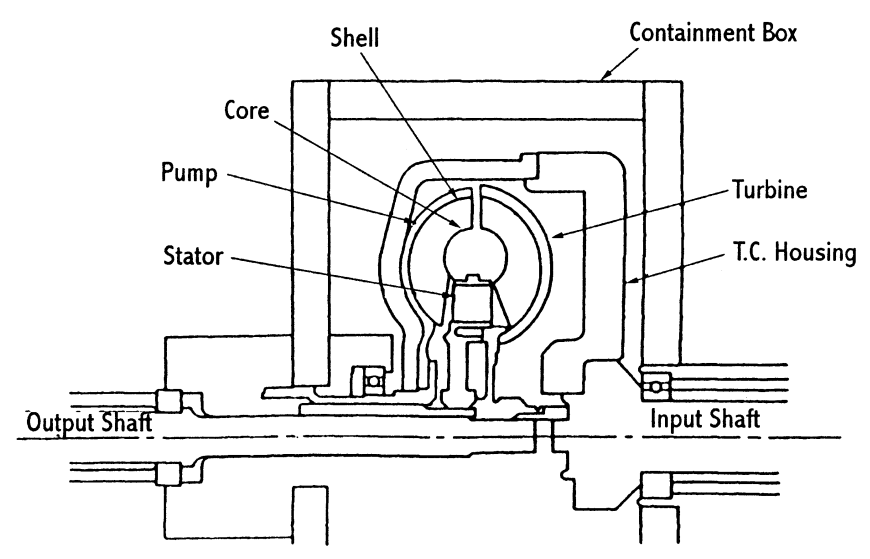

FIGURE 1

Cross-section of torque converter.

Yermakov (1998). For this article, it was used to measure the flow field in the pump's exit plane and in the turbine's inlet plane. The torque converter geometry was changed and had a larger axial length and, as a result, a longer flow passage than had been tested previously. The method described by Brun and Flack (1994) was employed to correlate laser velocimeter data with shaft angular position data to generate blade-to-blade profiles and to visualize the pump-exit and turbine-inlet flow fields. The primary purpose of this study was to show how the flow field changes at extreme speed ratios, namely, those well above the coupling point. For this research, the tested speed ratios were $0.065,0.6,0.8,0.875$, $0.95,1.00$, and 1.05 . The first three speed ratios were chosen because they correspond to the range of speed ratios previously tested. The 0.875 speed ratio corresponds to the coupling point of this torque converter. The 1.05 speed ratio was chosen because it is the maximum speed ratio that could be attained with this rig and torque converter. The 1.0 was chosen to determine

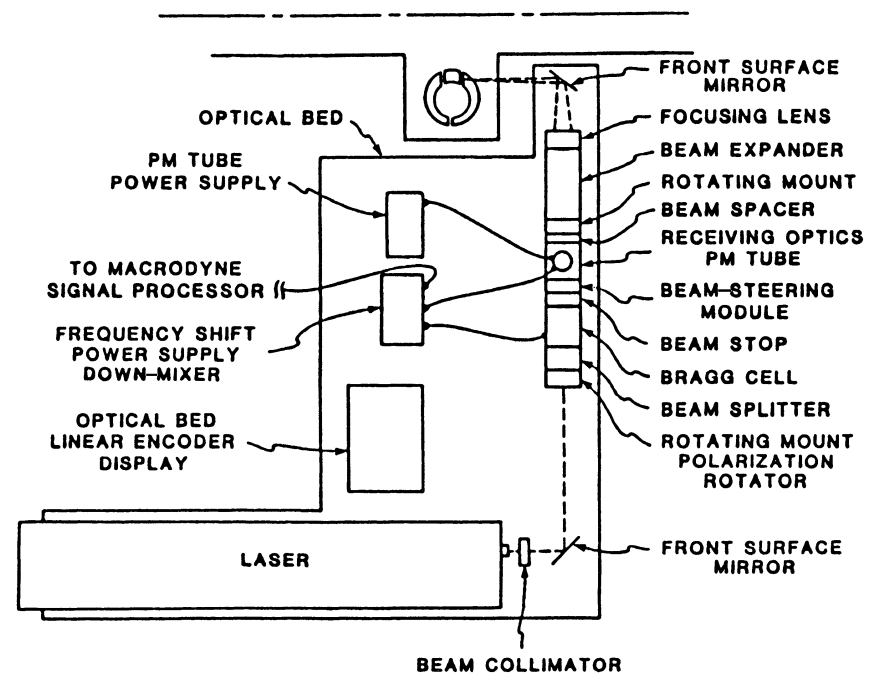

FIGURE 2

Torque converter and laser velocimetry system.

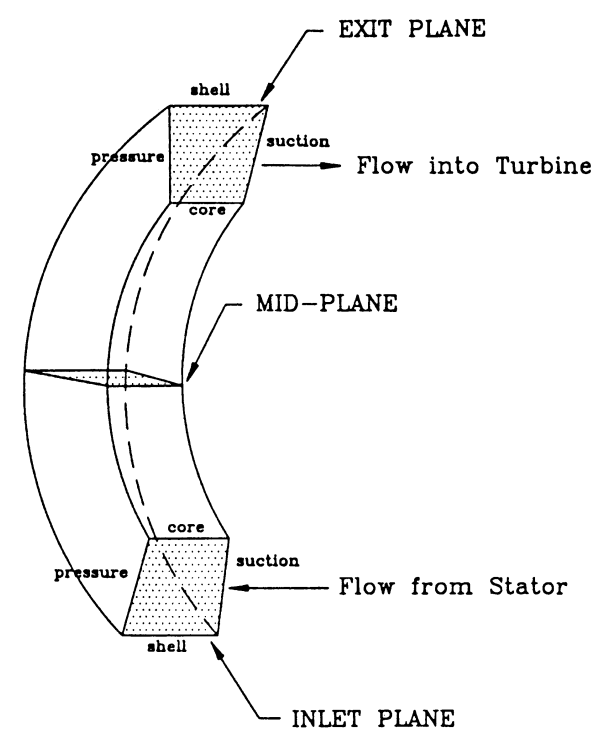

FIGURE 3

Pump passage geometry.

the flow field when the pump and turbine rotate at the same speed. And finally, the 0.95 speed ratio was chosen because it is the symmetrical value of 1.05 with respect to 1.0. Most important, although torque converters do operate above the coupling point on occasion, speed ratios above 0.8 are higher than previously documented for any geometry, so this effort significantly expands the published database of flows in torque converters.

\section{EXPERIMENTAL FACILITY}

Figure 1 displays the cross-section of the torque converter; Figure 2 shows the fixture with the laser velocimetry system; Figure 3 shows the general pump passage; Figure 4 shows the tubine passage. The rig was constructed of Plexiglas for optical

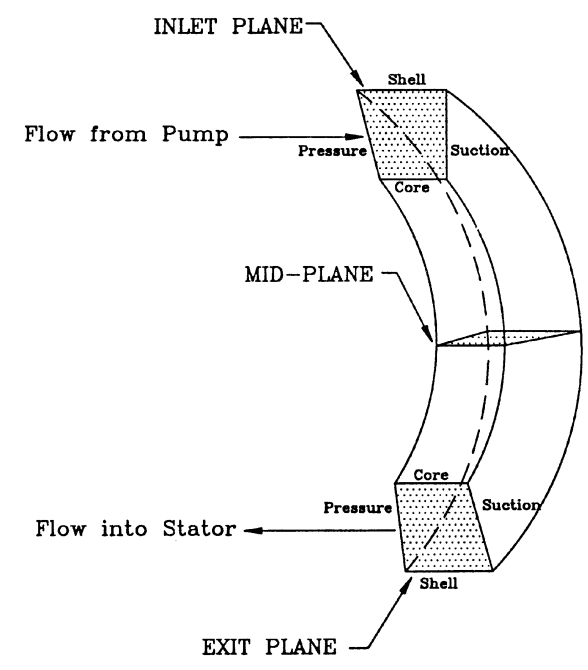

FIGURE 4

Turbine passage geometry. 
accessibility, and the working fluid was Shellflex 6212, which was chosen because the index of refraction matched that of Plexiglas. The torque converter was located in a sealed rectangular containment box also made of Plexiglas to reduce the effects of laser-beam refraction.

The torque converter pump was driven by a $18.6-\mathrm{kW}$ motor, and the rotational energy from the torque-converter turbine was absorbed by a $130.5-\mathrm{kW}$ eddy current dynamometer. A hydraulic system cooled, lubricated, and pressurized the torque-converter rig. The pressures and temperatures throughout the test fixture and support system were monitored and controlled. The pump and turbine rotational speeds were controlled to within $1 \mathrm{rpm}$.

For the velocity measurements, a one-directional backscatterburst laser velocimeter was employed. A 2-Watt argon-ion laser was operated at $50 \mathrm{~mW}$ and at a wavelength of $514.5 \mathrm{~nm}$. Two different transmitting lenses (focal lengths $250.8 \mathrm{~mm}$ and $350 \mathrm{~mm}$ ) and a mirror were used to access the torque converter from three Cartesian angles to obtain independently the threedimensional velocity field. The beam separation was $40 \mathrm{~mm}$, and the frequency shift was $40 \mathrm{MHz}$. The backscattered light was collected by the photomultiplier tube, downshifted by 2 $\mathrm{MHz}$, bandpass-filtered, and then transmitted to the burst processor, where the signal was amplified. To measure the three different velocity components, it was necessary to realign the optics. The transmitting and receiving optics were mounted on a mill table such that the probe volume could be moved accurately in all three directions by traversing the mill table. The position of the table and, thus, the measurement location (probe volume) were controlled by three-axis stepper motors, linear encoders, and a digital readout. The bursts were validated by using a minimum threshold setting to eliminate low-amplitude noise and by using a $\frac{5}{8}$ peak counter-comparator to eliminate multiple particle signals. Validated signals were digitized and transmitted to a microcomputer. Two 10-bit (1024 position) binary shaft encoders accessed the instantaneous angular positions of the pump and turbine of the torque converter for each valid velocity measurement. Using the angular positions from the pump and turbine shaft encoders, the velocities were then organized to generate the appropriate blade-to-blade (pressure surface-tosuction surface) velocity profiles, resulting in 32 and 28 pumpand turbine-measurement positions, respectively. Measurement locations were determined by using accurate reference points in the pump and turbine and the known dimensions. Data were taken for 10 equally spaced core surface-to-shell surface positions. The data for the rotating planes were finally resolved into $32 \times 10$ pump and $28 \times 10$ turbine measurement grids for the time-averaged flow field of the rotating coordinate system. Velocity profiles were numerically integrated across the flow areas to determine the mass flow rates.

Uncertainties in measured velocities were due to the clock in the digital processor, to uncertainties in the beam's crossing angle, and to the finite number of samples used to approximate the true distribution. Furthermore, uncertainties in position translate into uncertainties in the velocity when velocity gradients
TABLE 1

Specific Geometry Data

\begin{tabular}{lc}
\hline Outside diameter & $245 \mathrm{~mm}$ \\
Axial length & $76 \mathrm{~mm}$ \\
Number of pump blades & 32 \\
Pump inlet blade angle & $-29.9^{\circ}$ \\
Pump exit axial blade angle, $\beta_{\mathrm{e}}$ & $29.9^{\circ}$ \\
Number of turbine blades & 36 \\
Turbine inlet blade angle & $60.0^{\circ}$ \\
Turbine exit axial blade angle & $-60.0^{\circ}$ \\
Turbine inlet radial blade angle & $28.5^{\circ}$ \\
Number of stator blades & 14 \\
Stator inlet blade angle & $27^{\circ}$ \\
Stator exit blade angle & $70^{\circ}$ \\
\hline
\end{tabular}

are present. The total uncertainty resulting from the combination of these effects is typically $0.07 \mathrm{~m} / \mathrm{sec}$.

A scaled version of a truck torque converter was used for this research; it has a 245-mm-diameter torque converter, and it has a larger axial length than previously tested. Two previous 245-mm-diameter torque-converter geometries (different axial lengths and inner radii) were tested by Claudel (1997), Gruber (1999), Whitehead (1995), and Yermakov (1998) but were examined only for speed ratios up to 0.80 . Detailed comparisons of the three-dimensional flow fields (including the strong secondary flows) for all geometries and components will be documented in forthcoming papers, but in general, flow fields are best behaved in torque converters with long flow passages. For this geometry, the turbine inlet was $3 \mathrm{~mm}$ downstream of the pump's exit. The pump contained 32 identical, constant-thickness blades, and the turbine contained 36 identical, constant-thickness blades. The stator was composed of 14 airfoil-shaped blades. Specific geometric information about the components is presented in Table 1. All axial blade angles are given relative to the axial direction of the torque converter, with positive angles in the direction of rotation.

Test conditions are listed in Table 2. The pump was studied in detail for seven speed ratios (0.065 to 1.05). The stator's rotational speed was zero in all cases. The maximum Reynolds

TABLE 2

Test Conditions

\begin{tabular}{lccc}
\hline $\begin{array}{l}\text { Speed } \\
\text { ratio }\end{array}$ & $\begin{array}{c}\text { Pump speed, } \\
\text { rpm }\end{array}$ & $\begin{array}{c}\text { Turbine speed, } \\
\text { rpm }\end{array}$ & $\begin{array}{c}\text { Stator speed, } \\
\text { rpm }\end{array}$ \\
\hline 0.065 & 800 & 52 & 0 \\
0.6 & 1100 & 660 & 0 \\
0.8 & 1100 & 880 & 0 \\
0.875 & 1100 & 962 & 0 \\
0.95 & 1100 & 1045 & 0 \\
1.0 & 1100 & 1100 & 0 \\
1.05 & 1100 & 1155 & 0 \\
\hline
\end{tabular}




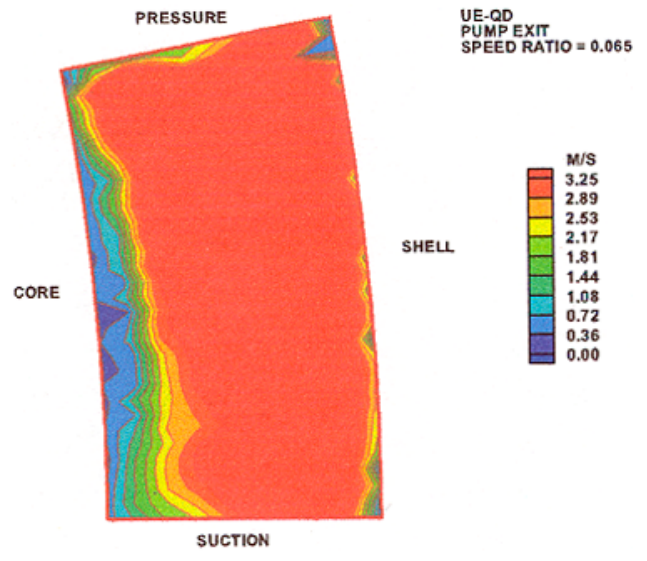

FIGURE 5

Pump exit; SR $=0.065$.

number based on the pump's exit passage's size and velocity was 2750 .

For the 0.065 speed ratio, the measurements were taken for a pump velocity of $800 \mathrm{rpm}$, and a correction was made using pump affinity laws to find the values of the velocities and of the mass flow when the pump was running at $1100 \mathrm{rpm}$. Running the rig at the low speed ratio and at higher speeds was not possible due to high blade loadings for these conditions. Thus, to find the equivalent mass flow at $1100 \mathrm{rpm}$, the flow rate $Q$ can be considered to be proportional to the pump's angular velocity, as shown by Flack and colleagues (2001), who also showed Reynolds-number independence:

$$
Q \propto \omega_{p}\left[\eta_{p}\left\{1-\frac{R_{1}}{R_{2}} \frac{c_{u 1}}{c_{u 2}}\right\}-\eta_{t}^{-1}\left\{1-\frac{R_{3}}{R_{2}} \frac{c_{u 3}}{c_{u 2}}\right\} \mathrm{SR}\right]^{1 / 2}
$$

where $\omega_{p}$ is the pump speed; $\eta_{p}$ and $\eta_{t}$ are the pump and turbine efficiencies; $R_{1}, R_{2}$, and $R_{3}$ are the radii at the pump inlet, pump exit/turbine inlet, and turbine exit, respectively; $c_{u 1}, c_{u 2}$, and

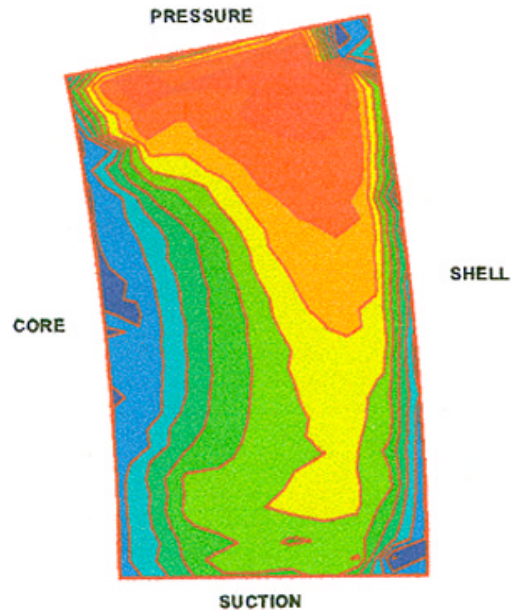

FIGURE 7

Pump exit; SR $=0.800$.

$c_{u 3}$ are the tangential fluid velocities at the pump inlet, pump exit/turbine inlet, and turbine exit, respectively; and SR is the speed ratio. Furthermore, the velocity fields are dynamically similar for the same speed ratio, except for a factor proportional to the pump's rotational speed.

Additional details about the experimental facility, data acquisition procedure, and measurement uncertainties, and detailed descriptions and dimensions of previous torque converters and passage geometries can be found in the work of Whitehead (1995) and Gruber (1999).

\section{RESULTS}

Tests were independently performed in both the pump exit and the turbine inlet with the objective of studying flow behavior at extreme speed ratios. For the data presented herein, only the through-flow component of velocity is presented.

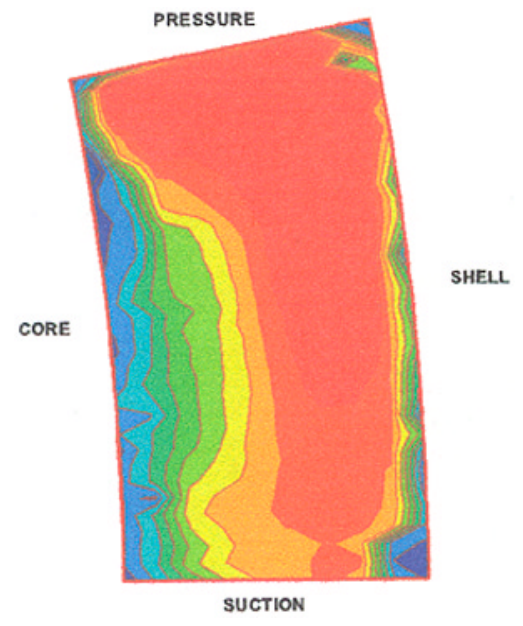

FIGURE 6

Pump exit; SR $=0.600$.

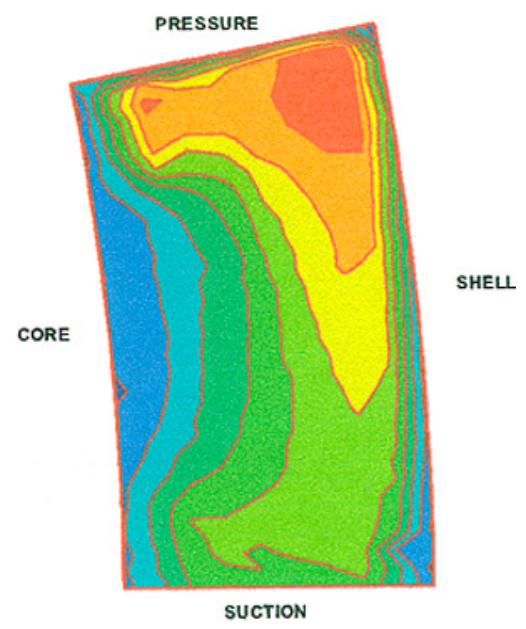

FIGURE 8

Pump exit; SR $=0.875$. 


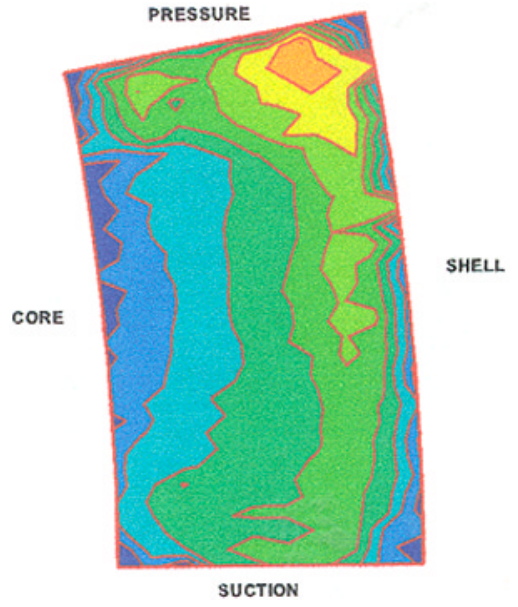

FIGURE 9

Pump exit; SR $=0.950$.

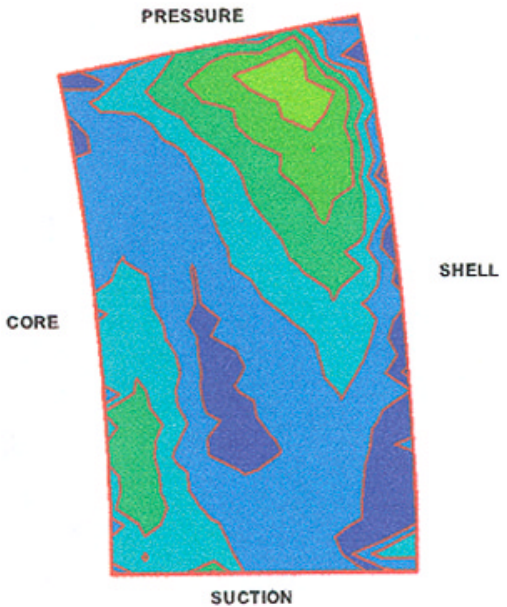

FIGURE 11

Pump exit; SR $=1.050$.

\section{Pump Exit}

Typical average through-flow velocity magnitudes for the pump exit are given in Figures 5 through 11; all have the same scales as those in Figure 5. These plots illustrate the flow field in the pump's exit plane at the various speed ratios. The plots show the magnitude of the though-flow velocities, and velocities are shown relative to the moving blades. The lines shown are the isovelocity lines, that is, constant through-flow velocity contours. The core surface, shell (housing) surface, blade suction surface, and blade pressure surface can be seen in these figures.

For the first two speed ratios $(0.065$ and 0.600$)$, as shown in Figures 5 and 6, the flow in the pump's exit plane was relatively uniform. At the 0.600 speed ratio, the area of the low-velocity zone close to the core side was larger than it was at the 0.065 speed ratio. In addition, the high-velocity area was concentrated on the pressure side of the blade passage as compared to the

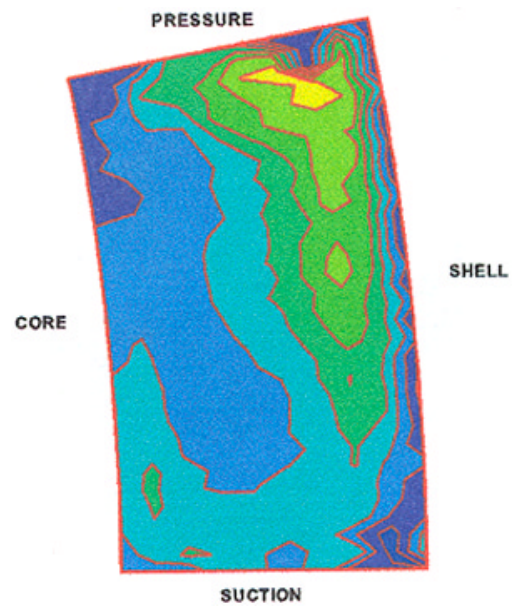

FIGURE 10

Pump exit; SR $=1.000$. lowest speed ratio; strong velocity gradients were seen at $\mathrm{SR}=$ 0.065 , near the core side.

The tendencies of the 0.600 speed ratio were verified with the 0.800 and 0.875 speed ratios, as shown in Figures 7 and 8 . The high-velocity area was very close to the pressure side of the passage. The low-velocity area was still increasing with increasing speed ratio. At the 0.875 speed ratio, the high velocity area was concentrated in the pressure-shell corner of the passage. Most significant were the gradients of the entire flow field near the coupling point. At these speed ratios, the areas of gradients were largest, indicating significant shear losses. Also, it should be remembered that the turbine inlet is directly downstream from the pump exit and rotates at a different speed. As a result, nonuniformities caused a highly periodic flow field into the turbine's passages. Such periodicity translate into fluctuating incidence

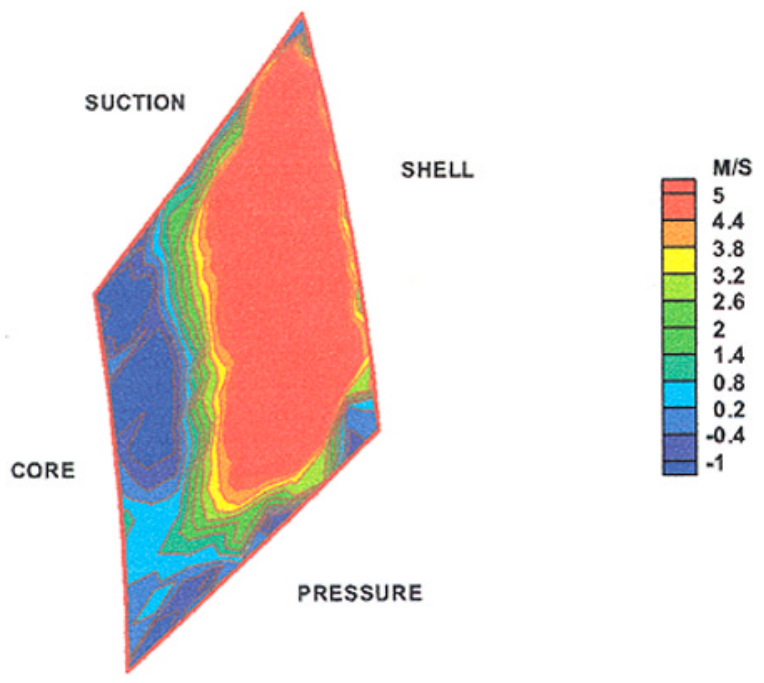

FIGURE 12

Turbine inlet; $\mathrm{SR}=0.065$. 


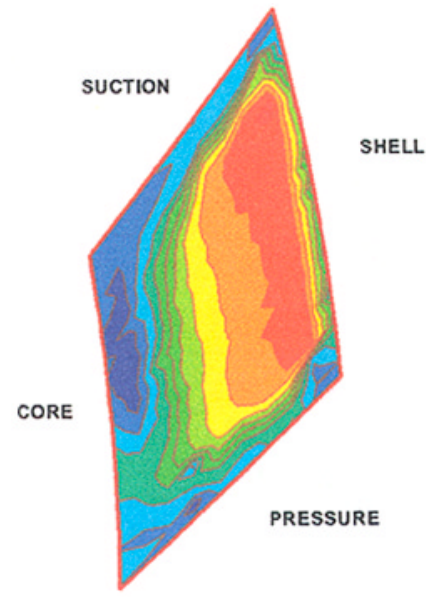

FIGURE 13

Turbine inlet; SR $=0.600$.

angles to the turbine blades and periodic separated regions in the turbine.

At the 0.95 and 1.00 speed ratios (Figs. 9 and 10), the velocities were low. The high-velocity area was once again concentrated on the pressure side of the passage. The tendency of the low-velocity area to increase was still present but that area extended from the core to the suction-shell corner. A small high velocity area appeared in the core suction corner.

At a speed ratio of 1.05 (Fig. 11), the high velocity areas were located in the core suction corner and in the pressure-shell corner. The low-velocity area extended from the pressure-core corner to the suction-shell corner, and separation is seen.

\section{Turbine Inlet}

As for the pump, the though-flow velocity fields were plotted for the turbine inlet. Figures 12 through 18 show the throughflow velocity fields for different speed ratios; all have the same

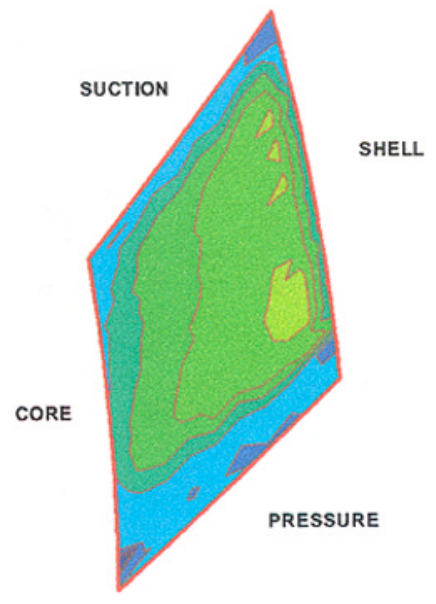

FIGURE 15

Turbine inlet; SR $=0.875$.

scales as those used in Figure 12. As for the pump's exit, velocities are shown relative to the moving blades.

At the pump's exit plane, the velocities were very high for the turbine inlet plane at the lowest two speed ratios (Figs. 12 and 13). In both cases, the high-velocity area was concentrated on the shell side. At the 0.065 speed ratio, an important negative flow occurred close to the core. It extended to about $1 / 4$ of the total area of the passage. The area of this region decreased at the 0.600 speed ratio, and the velocity gradient from the core to shell was also smoothed. This reversal is an indicator of flows moving from the turbine's inlet into the pump's inlet through the core, as will be discussed later in relationship to the mass flow. Also, velocity gradients were very large at low speed ratios, indicating that large shear losses occur under these conditions.

As the speed ratio increased to 0.80 and 0.875 (Figs. 14 and $15)$, the maximum velocity decreased. Instead of the peak of $6.5 \mathrm{~m} / \mathrm{sec}$ for the 0.065 speed ratio, the peak velocity dropped to $3 \mathrm{~m} / \mathrm{sec}$ for the 0.875 speed ratio. In addition, the negative

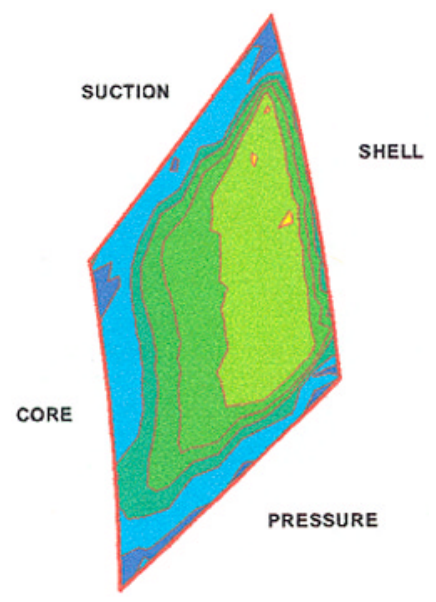

FIGURE 14

Turbine inlet; $\mathrm{SR}=0.800$.

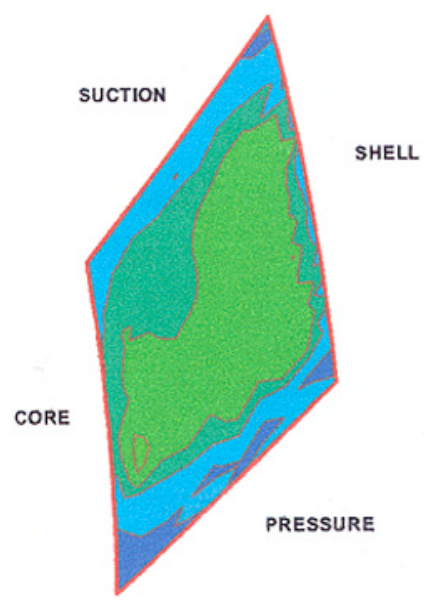

FIGURE 16

Turbine inlet; SR $=0.950$. 


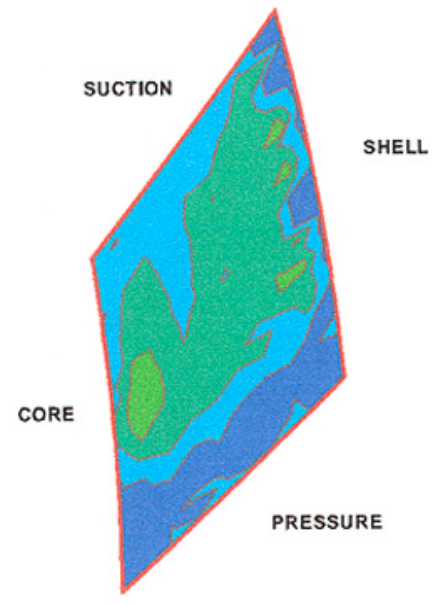

FIGURE 17

Turbine inlet; $\mathrm{SR}=1.000$.

velocity area disappeared. It is very important to note, however, that near the coupling point, the pump exit flow field was the most nonuniform of all of the speed ratios. That nonuniformity yielded a highly fluctuating flow into the turbine's inlet and resulted in periodic incidence angles at the turbine's inlet and in poor performance.

At the extreme speed ratios $(0.95,1.00$, and 1.05$)$, as shown in Figures 16 through 18, the flow tended to migrate from the shell to the core. At the 1.000 speed ratio, two high-velocity areas were located on the core and shell sides while a low velocity was found inbetween. For the speed ratio of 1.05, the high-velocity area was located only at the core side and had a peak velocity of $2.1 \mathrm{~m} / \mathrm{sec}$. The remainder of the passage had a uniform velocity of approximately $0.6 \mathrm{~m} / \mathrm{sec}$.

\section{Mass Flow Rates}

Mass flow rates at the pump exit plane and the turbine inlet plane were calculated by integrating, in two directions, the

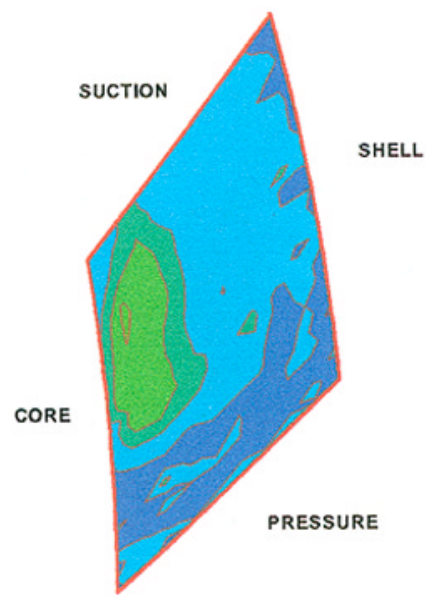

FIGURE 18

Turbine inlet; $\mathrm{SR}=1.050$.

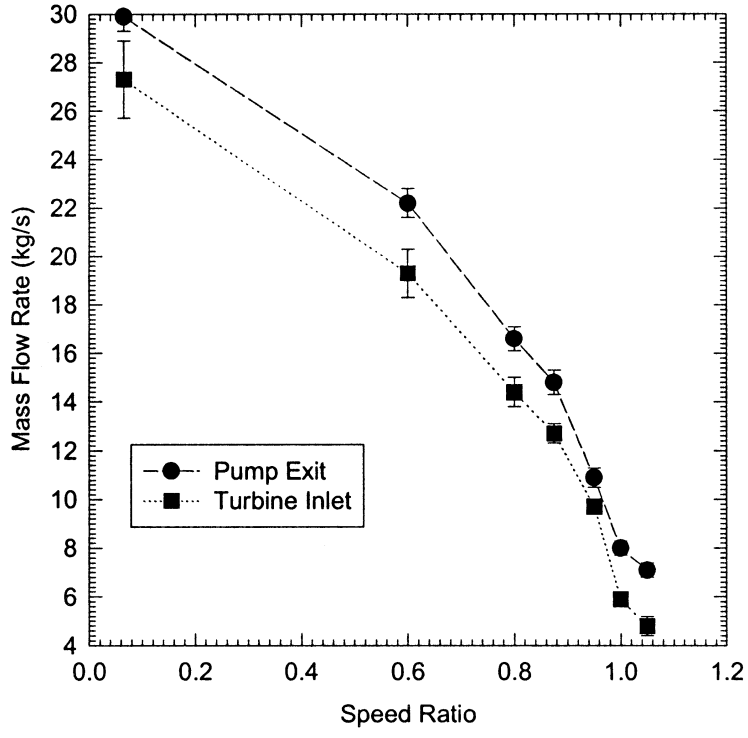

FIGURE 19

Dependence of mass flow rate on speed ratio.

average through-flow velocity, the incremental flow areas, and the oil density across the passage.

An uncertainty analysis of the mass flow rate was performed based on the uncertainty of the measurement's location position and on the uncertainty of the through-flow velocities. The results are given in Figure 19. Some differences in mass flow were observed.

The values of the mass flow rate showed that the mass flow was high for the speed ratio until 0.600 . Above 0.800 , the mass flow rapidly decreased as the speed ratio approached unity. However, the slope of the decrease changed suddenly when the speed ratio of 1.000 was reached, and although the mass flow continued to decrease, the decrease was not as rapid. The nonlinear behavior is generally predicted by Equation (1). The difference between the mass flow rate through the pump exit and the mass flow rate through the turbine inlet was a result of the clearance between those two planes. The clearance was larger than is found in a conventional operational torque converter; larger clearances were necessitated because of the Plexiglas components and the experimental apparatus. This clearance allowed part of the flow to bypass the turbine and go directly back to the low-pressure pump inlet through the torque converter's core region. This difference in mass flow rates also explains the reverse flow seen in the turbine but not seen in the pump at low speed ratios. This loss was about the same at all speed ratios and was approximately $2 \mathrm{~kg} / \mathrm{sec}$. It has been observed in previously tested torque converters.

\section{CONCLUSIONS}

A laser velocimeter was used to measure the velocity field through the pump-turbine interface of a torque converter. The torque converter was axially longer than any previously tested 
and, most important, the pump-turbine speed ratio was higher than any previously studied and documented. Results have been presented for speed ratios above the coupling point. Throughflow velocities have been presented for the pump exit and the turbine inlet passages. The important conclusions drawn from this investigation are as follows.

For the pump exit, as the speed ratio increases, the high velocities first move to the pressure-shell corner and then to both the core-suction and the pressure-shell corners. Concentrated velocity gradients are largest at the lowest speed ratio, but areas of velocity gradients are largest near the coupling point, indicating that large shear losses occur in these conditions. Also, near the coupling point, the flow field is least uniform, which yields a highly periodic flow into the turbine inlet. Such periodicity yields periodic incidence angles at the turbine inlet, which results in poor performance. Above the coupling point, the high velocity remains in the pressure-shell corner but, significantly, separation is seen to develop at the highest speed ratio.

For the turbine inlet, the flow is, in general, more uniform than for the pump at all speed ratios. However, reverse flow is seen at low speed ratios, which was not observed for the pump and which is an indicator of leakage through the core. Velocity gradients are very large at low speed ratios, again indicating that large shear losses occur in this regime. As the speed ratio increases to the coupling point, the high velocities remain on the shell side. Above the coupling point, the high-velocity flow migrates from the shell side to the core side.

The integrated mass flow decreases (with increasing negative slope) as the speed ratio increases to a speed ratio of unity. However, this slope decreases above the 1.00 speed ratio. Differences in the pump and turbine mass flow rates are a result of leakage through the core.

\section{REFERENCES}

Browarzik, B. 1994. Experimental investigation of rotor/rotor interaction in a hydrodynamic torque converter using hot-film anemometry. ASME Paper 94-GT-246. NY, NY: ASME.

Brun, K., and Flack, R. D. 1994. A method to measure periodic velocity fields in multi-element turbomachines with discrete sampling. Journal of Physics, E. Measurement Science Technology 418425.

Claudel, W. D. 1997. A Comparison of the Internal Flow Fields of Three Automotive Torque Converter Pumps using Laser Velocimetry (MS thesis, University of Virginia).

Ejiri, E., and Kubo, M. 1998. Influence of the flatness ratio of an automotive torque converter on hydrodynamic performance. ASME Paper No. FEDSM98-4866. NY, NY: ASME.

Flack, R. D., Gillies, G. T., Hotho, M., and Christen, B. 2001, MayJune Effect of rotational speed, speed ratio, and pump exit blade angle on the mass flow rate in a torque converter. Proceedings of ASME FEDSM'01, Paper No. FEDSM2001-18163. NY, NY: ASME.

Gruber, M. R. 1999. A Study of the Internal Flow Fields of Two Automotive Torque Converter Turbines Using Laser Velocimetry. (MS thesis, University of Virginia).

Marathe, B. V., and Lakshminarayana, B. 1997. Experimental investigation of steady and unsteady flow field upstream and downstream of an automotive torque converter pump. ASME Paper FEDSM973353. NY, NY: ASME.

Watanabe, H., Kurahashi, T., and Kojima, M. 1997. Flow visualization and measurement of torque converter stator blades using a laser sheet lighting method and a laser velocimeter. SAE Paper No. 970680. Detroit, MI: SAE.

Whitehead, L. D. 1995. A Comparison of the Internal Flow Fields of Two Automotive Torque Converters Using Laser Velocimetry. (MS thesis, University of Virginia).

Yermakov, A. 1998. A Study of the Internal Flow of Fields of Two Automotive Torque Converter Turbines Using Laser Velocimetry (MS thesis, University of Virginia). 

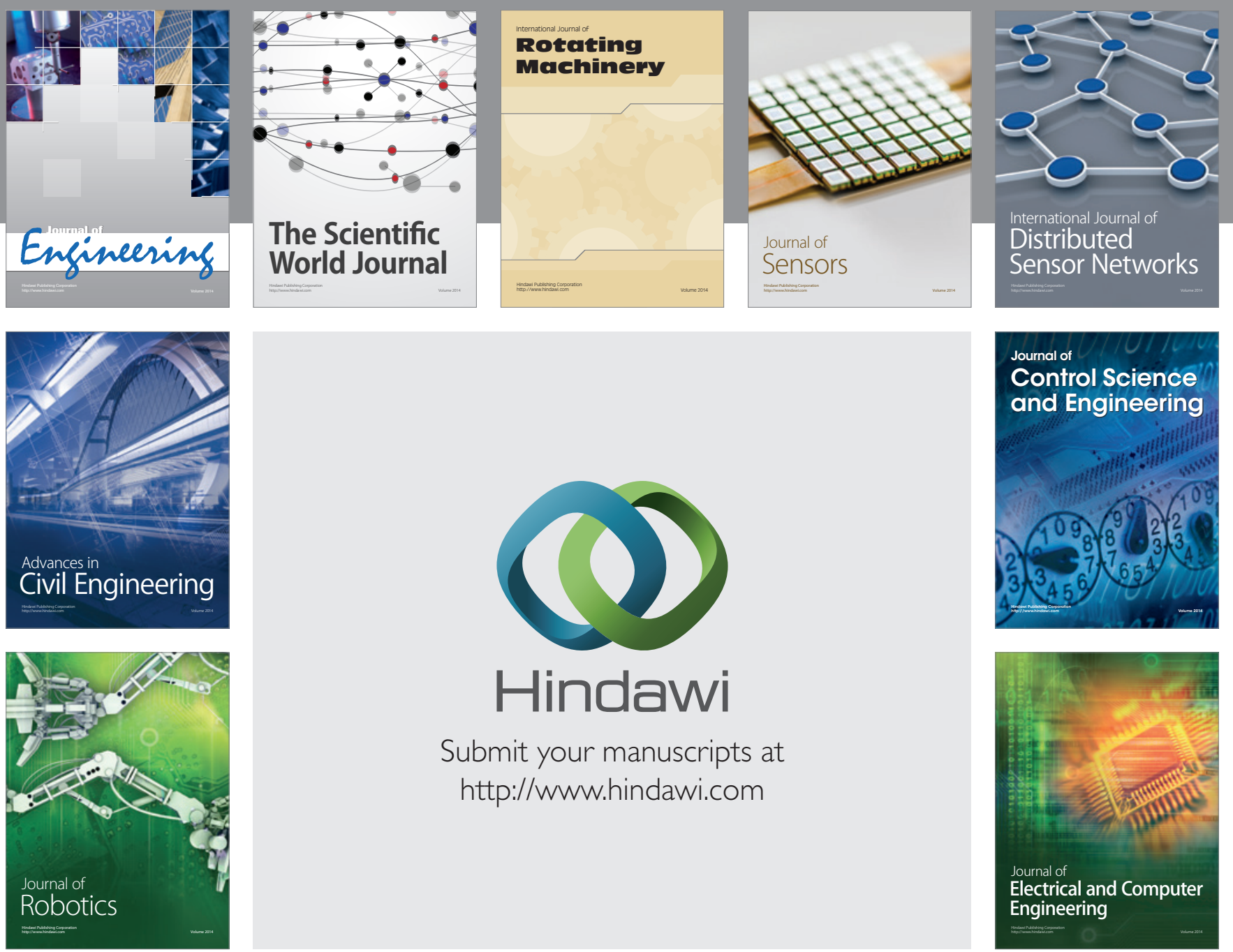

Submit your manuscripts at

http://www.hindawi.com
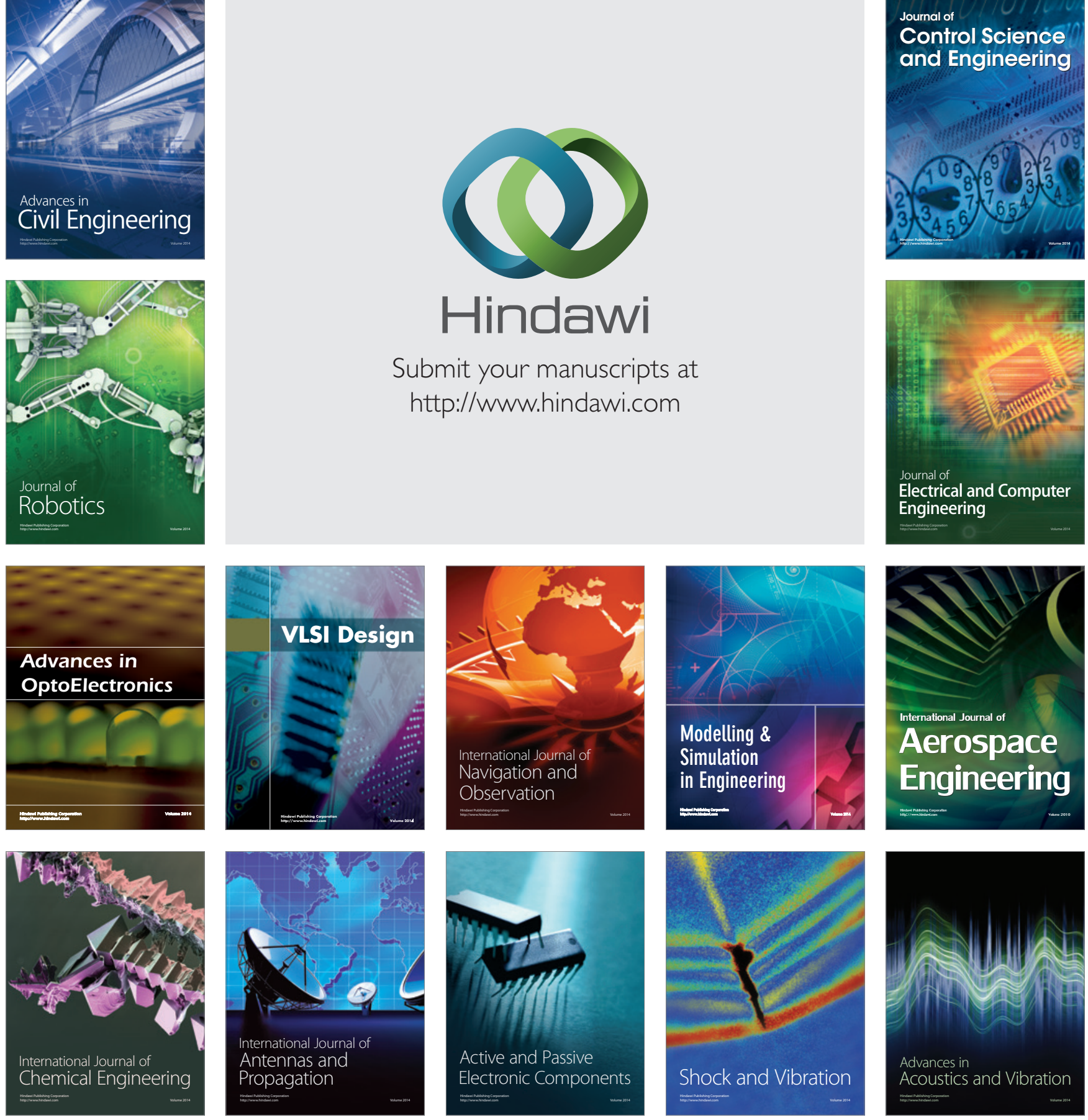